\title{
AS REPRESENTAÇÕES SOCIAIS DOS MORADORES \\ DA ÁREA DA BACIA HIDROGRÁFICA DO RIO CUBATÃO DO NORTE SOBRE O DESMATAMENTO DA MATA ATLÂNTICA (JOINVILLE-SC)
}

Vanilda Barbosa Galli*

${ }^{1}$ Nelma Baldin**

\section{INTRODUÇÃO}

O processo de ocupação do Brasil caracterizou-se pela falta de planejamento e consequente destruição dos recursos naturais, particularmente das florestas. A cobertura florestal nativa representada pelos diferentes biomas foi sendo fragmentada, cedendo espaço para as culturas agrícolas, as pastagens e as cidades (PAZ; FARIAS, 2008, p. 287).

Ao longo da história do país, a Mata Atlântica foi a primeira floresta a receber iniciativas de colonização. Dela saiu a primeira riqueza a ser explorada pelos colonizadores e, desde então, vários ciclos se desenvolveram no seu domínio. Porém, os colonizadores motivados pela valorização da madeira e pelo lucro fácil não percebiam a importância dos benefícios ambientais que a cobertura florestal nativa trazia e, assim, foram mais de quatro séculos de extração predatória, seletiva e exaustiva de espécies como o pau-brasil, além de outros produtos florestais que foram e são até hoje amplamente extraídos (DEAN, 1996).

A Bacia Hidrográfica do Rio Cubatão do Norte $(\mathrm{BHRCN})$ é considerada uma das mais importantes bacias hidrográficas da região nordeste de Santa Catarina. Por este motivo, faz-se necessário, enfatizar sobre esse tema tão importante para a preservação da Bacia Hidrográfica que é a Mata Atlântica. Sabese, da grande importância que a floresta tem para a permanência de um rio, ela é primordial para sua existência uma vez que estabelece profunda relação de proteção e preservação. Sabe-se, da grande importância que a floresta tem para a permanência de um rio, ela é primordial para sua existência uma vez que estabelece

1 * Doutoranda em Saúde e Meio Ambiente pela Universidade de Joinville (UNIVILLE). vanildagalli09@hotmail.com** Doutora em Educação (PUC/SP); Professora do programa de pós Graduação em Saúde e Meio Ambiente - Univille. nelma@univille.br 
profunda relação de proteção e preservação. Dessa forma, as questões ambientais vêm modificando o cenário mundial que está marcado por um processo acelerado de degradação e falta de comprometimento com o ambiente em que vivemos. A complexidade desses problemas nos remete a uma urgência na busca de alternativas de Educação Ambiental (EA) e na construção de uma visão consciente do espaço onde estamos inseridos. Atualmente, as discussões que envolvem a Educação Ambiental estão centradas nas questões mais gerais sem uma aproximação efetiva dos acadêmicos aos debates e reflexões que poderiam alterar comportamentos e atitudes diante do meio ambiente.

Neste sentido, o objetivo da pesquisa aqui destacado centra-se na análise de como se deu historicamente o processo de degradação da área da (BHRCN), revelando suas causas e consequências na economia e na história do desmatamento da Mata Atlântica que rodeava e rodeia o rio Cubatão (Joinville-SC).

\section{METODOLOGIA}

A pesquisa será desenvolvida na abordagem qualitativa e será descritiva de forma etnográfica. Esse tipo de pesquisa, segundo Lüdke e André (2003), tem sido o método sugerido para estudos que tem o ambiente natural como fonte dos dados. Nessa direção, o pesquisador é um importante instrumento pois precisa observar, coletar os dados, preocupar-se com o processo e atentar para o significado que as pessoas dão para as coisas, para o contexto no qual essas informações estão inseridas. Portanto, não será uma observação comum que gerará apenas dados para a pesquisa, mas sim, será uma questão previamente definida, buscando relacionar um conhecimento aprofundado sobre $\mathrm{o}$ assunto em questão que, no caso, é o fenômeno que levou ao desmatamento da mata ciliar que rodeava o Rio Cubatão do Norte. Para a coleta de dados, será realizado uma entrevista aberta e semiestruturada há 50 moradores da região, tendo como critério para a participação (morar 40 anos ou mais na localidade).

O centro desta pesquisa será a área da Bacia Hidrográfica do Rio Cubatão do Norte (BHRCN). O Rio Cubatão do Norte será o objeto central do estudo, e a Mata Atlântica - especificamente a mata ciliar formada pela Mata Atlântica - que circundava o Rio Cubatão do Norte será o ponto de partida do estudo. A área da BHRCN é bastante extensa $\left(492 \mathrm{~km}^{2}\right)$, para tanto, foram definidos 
15 pontos estratégicos, conforme as quantidades dos principais afluentes-rios que formam a bacia onde se concentrará a pesquisa, mais especificamente, onde se dará a busca dos dados e a delimitação do estudo.

Esses 15 pontos foram definidos como o locus da pesquisa porque são os principais afluentes da BHRCN, no entanto, um ponto, o afluente Rio do Braço, já se tem informações detalhadas obtidas no estudo anterior de Galli (2014), neste sentido a pesquisa centrar-se-á em 14 pontos. Buscar-se-á saber dos residentes dessas localidades a serem estudadas: o que percebem como comprometedor da qualidade das águas de seus rios, notadamente afluentes do Rio Cubatão do Norte; qual a relação da Mata Atlântica com as águas do Rio Cubatão; e quais as percepções e representações sociais que têm sobre o fenômeno que ocorre com esse rio, qual a percepção que expressam quanto à degradação da BHRCN. A referência da população para este estudo será a mata ciliar da área da bacia hidrográfica.

\section{População alvo e a técnica aplicada para contatá-los: a snowball}

Os sujeitos da pesquisa serão os habitantes mais antigos da região da área da $\mathrm{BHRCN}$, por onde corre o Rio Cubatão. O critério para definir qual a população que será entrevistada é de que seja considerado "como morador (a) mais antigo (a) da localidade" e esses indivíduos que serão entrevistados, serão indicados pelos próprios habitantes da BHRCN, na aplicação da técnica Snowball ("Bola de Neve").

Nesta pesquisa, para ser considerado "morador (a) mais antigo (a)", cada uma dessas pessoas terá de ser habitante tanto da zona urbanizada como da zona rural da área da Bacia Hidrográfica do Rio Cubatão do Norte - (município de Joinville) há pelo menos de 40 a 50 anos ou mais. Deverão ter sido indicados, à pesquisadora, de forma aleatória por pelo menos três moradores locais e considerados "lideranças" nas comunidades, conforme as diretrizes da técnica Snowball. Essas lideranças "indicadoras" dos sujeitos a serem entrevistados podem ser identificadas como sendo: agentes políticos; educacionais; econômicos; sociais e da saúde referenciados como vereadores; diretores de escolas; professores; comerciantes; empresários; agentes comunitários de saúde; e lideranças religiosas ou, ainda, cidadãos envolvidos com as questões educacionais, sociais, culturais, históricas e ambientais na localidade. Nesse sentido, a pesquisa não define de 
pronto um número exato e fechado de entrevistados, porque esse é um processo que irá se "construindo" ao longo da aplicação das ações da Snowball. No entanto, está-se, aqui, definindo um número mínimo para se trabalhar: 50 (cinquenta) pessoas, indicadas. A análise das falas desses sujeitos entrevistados será feita considerando-se os critérios das "histórias de vida". As "histórias de vida" aqui mencionadas significam o que se constitui como "conteúdo" ou dado coletado a partir das condições materiais da existência dos entrevistados e devem ser apreendidas como um processo que se dá em cada momento histórico, sendo, por isto, um processo complexo e dinâmico, contraditório e inacabado (BALDIN, 2011).

A técnica a ser utilizada, a Snowball, ("Bola de Neve"), possibilitará encontrar essa população-alvo. Essa técnica consiste em uma modalidade de pesquisa indicada para se trabalhar com Educação Ambiental aplicada em comunidades, e funciona como uma ferramenta para esse tipo de pesquisas (BALDIN, 2011).

Wha (1994) apud Baldin (2011), define que essa técnica é uma forma de amostra não probabilística utilizada em pesquisas sociais em que os participantes iniciais de um estudo indicam novos participantes, que por sua vez indicam novos participantes e assim sucessivamente, até que seja alcançado o número esperado (o número mínimo). A partir daí o pesquisador terá a sua população alvo definida, podendo dar início à sua pesquisa. Esse momento é também conhecido, na Snowball, como o "ponto de saturação". No caso desta pesquisa, o "ponto de saturação" para a definição dos entrevistados se dará quando os novos "indicadores" começarem a repetir os nomes dos já indicados para participarem da pesquisa, ou, então, quando os novos entrevistados passam a repetir os conteúdos já obtidos em entrevistas anteriores, sem acrescentar novas informações relevantes à pesquisa. Assim, segundo Baldin (2011), quando as informações já não trazem "algo novo" para a pesquisa, mas se repetem, é para o pesquisador a demonstração de que os dados já não mais contribuirão com novas informações. Portanto, a Snowball é uma técnica de amostragem que utiliza cadeias de referência, uma espécie de rede (BALDIN, 2011).

\section{RESULTADOS ESPERADOS}


Como a pesquisa ainda está em andamento e considerando que o projeto até este momento encontra-se em análise no Comitê de Ética da Univille, não há resultados a serem apresentados, mas acredita-se que com a aplicação da pesquisa será possível alcançar contribuições científicas e sociais que possibilitarão, à comunidade local, uma maior reflexão quanto à importância de preservar e cuidar das águas do Rio do Cubatão e da mata ciliar decorrente da Mata Atlântica.

Os resultados desta pesquisa poderão fornecer evidências de que a destruição da mata ciliar é uma prática realizada até mesmo antes da colonização (DEAN, 1996). Diante deste discurso, será ainda motivo de reflexão onde o estudo será aplicado, principalmente porque irá resgatar fatos históricos de âmbito ambiental da localidade e, sobretudo, voltado principalmente à sensibilização e conscientização dos moradores da área da BHRCN. Ainda, poderá, também, apresentar sugestões para conservação do Rio Cubatão no município de Joinville. Assim, espera-se que esta pesquisa subsidie a elaboração de campanhas e projetos de intervenção ambiental, envolvendo os sujeitos locais como um todo: governo e sociedade.

A previsão de início da pesquisa é agosto/2016 e a sua finalização em julho/2017.

\section{REFERÊNCIAS}

BALDIN, N.; MUNHOZ, E. M. B. Educação ambiental comunitária: uma experiência com a técnica de pesquisa snowball (bola de neve). Revista eletrônica do mestrado de educação ambiental, Rio Grande, v. 27, p. 46-60, jul./dez. 2011.

DEAN, W. A ferro e fogo: a história e a devastação da Mata Atlântica brasileira. São Paulo: Cia. das Letras, 1996. 67 p.

GALLI, V. B. História e economia: o desmatamento da mata atlântica - um sinal de desgaste nos meandros da bacia hidrográfica do rio Cubatão do norte (Pirabeiraba - Joinville, Santa Catarina) as percepções de seus moradores. Dissertação (Mestrado em Saúde e Meio Ambiente) - Univille, 2014.

LÜDKE, M.; ANDRÉ, M. E. D. A. Pesquisa em educação: abordagens qualitativas. São Paulo: EPU, 2003. 99 p.

PAZ, R. J; FARIAS T. (Org.). Gestão de áreas protegidas: processos e casos particulares. João Pessoa: Editora Universitária/UFPB, 2008. 
ZANOTELLI, C. T.; HOMRICH, A. P. M.; OLIVEIRA, F. A. Conhecendo a bacia hidrográfica do Rio Cubatão do Norte. Joinville, SC: UNIVILLE, 2009. 